\title{
Dynamic proteomic changes in soft wheat seeds during accelerated ageing
}

\author{
Yangyong Lv ${ }^{1}$ ， Pingping Tian ${ }^{1}$ ， Shuaibing Zhang ${ }^{1}$ ， Jinshui Wang ${ }^{1}$ ， Yuansen Hu Corresp. 1 \\ ${ }^{1}$ College of Biological Engineering, Henan University of Technology, Zhengzhou, China \\ Corresponding Author: Yuansen $\mathrm{Hu}$ \\ Email address: huyuansen@haut.edu.cn
}

Previous research demonstrated that soft wheat cultivars have better post-harvest storage tolerance than harder cultivars during accelerated ageing. To better understand this phenomenon, a tandem mass tag-based quantitative proteomic analysis of soft wheat seeds was performed at different storage times during accelerated ageing (germination ratios of $97 \%, 45 \%, 28 \%$, and $6 \%$ ). A total of 1010 proteins were differentially regulated, of which 519 and 491 were up- and downregulated, respectively. Most of the differentially expressed proteins were predicted to be involved in nutrient reservoir, enzyme activity and regulation, energy and metabolism, and response to stimulus functions, consistent with processes occurring in hard wheat during artificial ageing. Notably, defenseassociated proteins including wheatwin-2, pathogenesis-related proteins protecting against fungal invasion, and glutathione S-transferase and glutathione synthetase participating in reactive oxygen species (ROS) detoxification, were upregulated compared to levels in hard wheat during accelerated ageing. These upregulated proteins might be responsible for the superior post-harvest storage-tolerance of soft wheat cultivars during accelerated ageing compared with hard wheat. Although accelerated ageing could not fully mimic natural ageing, our findings provided novel dynamic proteomic insight into soft wheat seeds during seed deterioration. 
3 College of Biological Engineering, Henan University of Technology, Zhengzhou, PR China

5 *Corresponding author: Yuansen $\mathrm{Hu}$

6 Phone: +8637167756513

7 Fax: +8637167756513

8 E-mail: huyuansen@haut.edu.cn 


\section{Abstract}

11 Previous research demonstrated that soft wheat cultivars have better post-harvest storage tolerance

12 than harder cultivars during accelerated ageing. To better understand this phenomenon, a tandem

13 mass tag-based quantitative proteomic analysis of soft wheat seeds was performed at different

14 storage times during accelerated ageing (germination ratios of 97\%, 45\%, 28\%, and 6\%). A total of 1010 proteins were differentially regulated, of which 519 and 491 were up- and downregulated, respectively. Most of the differentially expressed proteins were predicted to be involved in nutrient reservoir, enzyme activity and regulation, energy and metabolism, and response to stimulus functions, consistent with processes occurring in hard wheat during artificial ageing. Notably, defense-associated proteins including wheatwin-2, pathogenesis-related proteins protecting against fungal invasion, and glutathione S-transferase and glutathione synthetase participating in reactive oxygen species (ROS) detoxification, were upregulated compared to levels in hard wheat during accelerated ageing. These upregulated proteins might be responsible for the superior postharvest storage-tolerance of soft wheat cultivars during accelerated ageing compared with hard wheat. Although accelerated ageing could not fully mimic natural ageing, our findings provided novel dynamic proteomic insight into soft wheat seeds during seed deterioration.

Keywords: soft wheat seeds; accelerated ageing; proteomics; post-harvest storage-tolerance.

\section{Introduction}

Wheat (Triticum aestivum L.), one of the most important crops in the world, is a staple food used for making flour, noodles, alcoholic beverages, biofuel and a variety of other products (Lim, 2013). The post-harvest storage of wheat seeds is commonly carried out in horizontal warehouses for 3 
to 5 years or longer in several northern provinces in China. As storage time is prolonged, seeds can deteriorate via incremental decomposition of stored substances, and impaired metabolism and energy supply, ultimately leading to commercial losses. Two of the most significant environmental factors affecting this process are temperature and relative humidity (McDonald, 1999). Extensive studies have been conducted to investigate physiological and biochemical changes during seed ageing. These researches indicate that accumulated free radicals attack membrane lipids, triggering degenerative events including changes in lipid content, nutrients reserves, lipoxygen activity and nucleic acids (Hu et al., 2012; McDonald, 1999; Rehman and Shah, 1999).

To study seed deterioration, accelerated ageing of seeds at high temperature and relative humidity for short durations was performed to evaluate storage potential. This method has been extensively used by researchers to investigate natural ageing (Galleschi et al., 2002; Calucci et al., 2004; Xin et al., 2011). Several researchers concluded that physiological changes in seeds subjected to accelerated ageing were the same as those occurring during natural ageing, only the rate differs, whereas others believe that artificial ageing treatments cannot replicate the actual seed status during storage, and question whether physiological changes during accelerated ageing reflect events during natural ageing (McDonald, 1999; Rajjou et al., 2008; Walters, 1998). In wheat, kernel texture and biochemical composition vary with the degree of hardness (Lesage et al., 2011; Pasha et al., 2010). Previous researches showed that seed ageing causes the physiological and biochemical variation including differences in hardness during storage, and these changed characteristics have been extensively studied, specifically changes in antioxidants, free radicals, storage proteins, and respiration (Galleschi et al., 2002; Calucci et al., 2004; Keskin et al., 2018; 
52 McDonald, 1999; Zhang et al., 2017). Previous studies also indicate that the seed ageing effects

53 the proteome of dry seeds (Rajjou et al., 2008; Xin et al., 2011). Additionally, proteomic changes

54 occur in medium-hard wheat seeds of the 'Aikang58' cultivar during deterioration, as evidenced

by 162 differentially expressed proteins (DEPs), confirming proteome variation in dry seeds during artificial ageing (Lv et al., 2016). Most previous studies have focused on quality, physiological and biochemical changes during storage, whereas dynamic quantitative proteomic changes in wheat seeds, especially those in soft wheat seeds that take place during accelerated ageing remain to be elucidated.

reagents, such as tandem mass tags (TMT) and isobaric tags for relative and absolute quantification (iTRAQ) (Karp et al., 2010; van et al., 2009). In this work, we conducted the first tandem mass tag (TMT)-based dynamic quantitative proteomic analysis of the seeds of the elite Chinese soft wheat cultivar 'Yangmai 15' during artificial ageing. The identified DEPs were associated with a range of different functions and provided new insight into the comprehensive understanding of deterioration in soft wheat seeds.

\section{Materials and methods}

\subsection{Wheat seeds and artificial ageing treatment}


73 The 'Yangmai 15' soft cultivars used in this study were purchased from the Henan Academy of

74 Agricultural Science. The original germination rate (Gr) was 97.0\% (designated as YM97), and

75 the average seed moisture content was $12.19 \%$. A $400 \mathrm{~g}$ sample of seeds with a similar size and

76 weight was stored in a $5 \mathrm{~L}$ plastic bottle at $45 \pm 1{ }^{\circ} \mathrm{C}$ and $50 \%$ relative humidity in a constant

77 temperature- and humidity-controlled cabinet (Binder KMF720, Tuttingen, Germany) according

78 to our previous research ( $\mathrm{Lv}$ et al., 2016). Measurement of $\mathrm{CO}_{2}$ from wheat respiration and

79 calculation of Gr were performed as previously described (Dong et al., 2015; Zhang et al., 2014).

$80 \mathrm{Gr}$ and the $\mathrm{CO}_{2}$ concentration were determined regularly and seed samples with three lots of

81 biological replicates were collected for further proteomic analysis when Gr was 97\%, 45\%, 28\%

82 and 6\% (designated as YM97, YM45, YM28 and YM6, respectively).

83 2.2. Protein extraction, SDS-PAGE analysis, trypsin digestion, TMT labelling and high-pressure

84 liquid chromatography (HPLC) fractionation

85 Protein extraction, trypsin digestion and HPLC fractionation were performed as reported

86 previously (Lv et al., 2016). Extracted proteins were boiled in loading buffer (100 mM Tris- $\mathrm{HCl}$

87 buffer ( $\mathrm{pH} 8.0$ ) containing $2 \% \mathrm{SDS}, 5 \%$ glycerol, and $1 \% \beta$-mercaptoethanol) for 5 min. They

88 were centrifuged at $12,000 \times \mathrm{g}$ for $5 \mathrm{~min}$, and supernatants were subjected to $12 \% \mathrm{SDS}-\mathrm{PAGE}$ in

89 a vertical slab gel apparatus (LIUYI, Beijing China). After trypsin digestion, peptides were

90 desalted using a Strata X C18 SPE column (Phenomenex, Torrance, CA, USA) and vacuum-dried.

91 Peptides were reconstituted in $0.5 \mathrm{M}$ triethylammonium bicarbonate and processed according to

92 the manufacturer's protocol for the TMT kit (Thermo Fisher Scientific, Waltham, MA, USA).

93 Briefly, one unit of TMT reagent was thawed and reconstituted in acetonitrile, and peptides from 
94 YM97, YM45, YM28, and YM6 (labelled with 126, 127, 130, and 131, respectively) were then

95

96 incubated with TMT reagent for $2 \mathrm{~h}$ at room temperature and pooled, desalted and dried by vacuum centrifugation. Labeled samples combined for further analysis.

2.3. Liquid chromatography tandem mass spectrometry (LC-MS/MS) analysis and database searches

LC-MS/MS and database searches were performed as described previously (Lv et al., 2016). Briefly, peptides were dissolved in $0.1 \%$ formic acid (solvent A) and separated using a reversedphase analytical column (Acclaim PepMap RSLC, Thermo Fisher Scientific). The gradient comprised an increase from $6 \%$ to $23 \%$ solvent B (0.1\% formic acid in $98 \%$ acetonitrile) over 26 min, $23 \%$ to $35 \%$ in $8 \mathrm{~min}$, an increase to $80 \%$ in $3 \mathrm{~min}$, and holding at $80 \%$ for $3 \mathrm{~min}$, all at a constant flow rate of $400 \mathrm{~nL} / \mathrm{min}$ on an EASY-nLC 1000 UPLC system. The resulting peptides were analyzed and subjected to a nanospray ion source followed by tandem mass spectrometry (MS/MS) in a Q Exactive ${ }^{\mathrm{TM}}$ instrument (Thermo Fisher Scientific) coupled online to an ultraperformance LC module. Peptides were selected for MS/MS using NCE setting of 28, and fragments were detected in the Orbitrap at a resolution of 17,500. A data-dependent procedure that alternated between one MS scan followed by $20 \mathrm{MS} / \mathrm{MS}$ scans with $15.0 \mathrm{~s}$ dynamic exclusion. The resulting MS/MS data were processed using the MaxQuant search engine (v.1.5.2.8). Tandem mass spectra were used as queries against the Uniprot_Triticum_aestivum database $(136,892$ sequences) concatenated with the reverse decoy database. The false discovery rate was adjusted to $<1 \%$, and the minimum score for peptides was set at $>40$. Proteins displaying a 1.2 -fold change 
114 between artificially aged and normal seeds (YM45 vs. YM97, YM28 vs. YM97 and YM6 vs.

115 YM97) were considered as DEPs if $\mathrm{p}<0.05$.

116 2.4. Protein annotation and functional enrichment analysis

117 Gene Ontology (GO) annotation and Kyoto Encyclopedia of Genes and Genomes (KEGG)

118 analyses were performed as previously described (Wu et al., 2006). Additionally, domain

119 annotation and subcellular localization were performed using InterProScan on InterPro

120 (http://www.ebi.ac.uk/interpro/) and WoLFPSORT systems (PSORT/PSORT version II;

121 http://psort.hgc.jp/), respectively (Horton et al., 2007; Zdobnov et al., 2011). Functional-

122 enrichment-based clustering for different protein groups (GO, Domain, Pathway) was performed

123 and cluster membership was visualized using a heat map generated with the "heatmap.2" function

124 in the "gplots" program within the R package as previous reported (Lv et al., 2016).

\section{3. Results}

3.1. Seed respiration and germination rate are altered during accelerated ageing

127 To characterize physiological changes occurring during artificial ageing, respiration and Gr were

128 investigated (Figure 1). The Gr of seeds following artificial ageing treatment displayed decreased

129 germinability from $97 \%$ to $87 \%$ (30 days), $70 \%$ (60 days), $45 \%$ (90days), $28 \%$ (120 days), $15 \%$

130 (150 days), and 6\% (180 days), while the amount of $\mathrm{CO}_{2}$ produced increased from $0 \%$ to $0.25 \%$

131 (30 days), $0.30 \%$ (60 days), 0.34\% (90 days), 0.37\% (120 days), 0.39\% (150 days), and $0.40 \%$

132 (180 days). These results showed that $\mathrm{Gr}$ and respiration changed rapidly from $30 \mathrm{~d}$ to $90 \mathrm{~d}$

133 indicating drastic seed vigor and metabolic alterations.

134 3.2. Overview of quantitative proteomics analysis 
135 To characterize the wheat seed proteome, a TMT-based gel-free quantitative proteomics analysis

136 of seeds with three biological replicates was performed during artificial ageing. Sodium dodecyl

137 sulfate-polyacrylamide gel electrophoresis (SDS-PAGE) analysis of proteins from wheat seeds is

138 shown in supplementary figure $1 \mathrm{~A}$. Each lane was loaded with $30 \mu \mathrm{g}$ of protein, and proteins of

139 different molecular weight were distributed in each lane, indicating that the protein was not

140 degraded and hence suitable for subsequent analysis. For LC-MS/MS analysis, distribution of

141 peptide length $(8-16)$, mass error $(<0.02 \mathrm{Da})$, and repeatability of relative protein quantitation

142 evaluation (characterized with pair-wise Pearson's correlation coefficients) indicated that MS data

143 accuracy, sample preparation, and reproducibility were acceptable (Supplementary Figure 1B-D).

144 In this study, 6271 proteins were identified, among which 4509 were quantified. Of the quantified

145 proteins, 1010 displayed significant changes, of which 519 were upregulated $($ ratio $>1.2 ; p<0.05)$

146 and 491 were downregulated (ratio $<1 / 1.2 ; p<0.05$ ) in the artificial aged seeds compared with

147 untreated (control) seeds (Supplementary Table 1). Of the upregulated proteins, there were 29 in

148 YM45 vs. YM97, 46 in YM28 vs. YM97, and 444 in YM6 vs. YM97; of the downregulated

149 proteins, there were 36 in YM45 vs. YM97, 28 in YM28 vs. YM97, and 427 in YM6 vs. YM97.

150 The above results showed that most of the DEPs distributed in YM6 (Gr was 6\%) compared with

151 YM97, indicating that the proteomic profiles were significantly changed during accelerated

152 ageing. The mass spectrometry proteomics data have been deposited to the ProteomeXchange

153 Consortium via the PRIDE (Vizcaíno et al., 2016) partner repository with the dataset identifier

154 PXD009156.

155 3.3. Protein annotation and functional enrichment analysis of DEPs 
156 To determine the functions of the quantified DEPs, annotation and functional enrichment analyses

157 were performed including subcellular localization, GO, domain, and pathway analysis

158 (Supplementary Table 1). To better understand the dynamics of DEPs during accelerated ageing,

159 a hierarchical clustering analysis was carried out to obtain dynamic expression patterns (Figure 2

160 and Figure 3). The biological process category of GO analysis indicated that upregulated proteins

161 involved in resistance (wheatwin and defensin-like proteins), killing of cells of other organisms,

162 and disruption of cells of other organisms were enriched in YM28. Additionally, upregulated

163 proteins participating in macromolecular metabolic processes were also enriched in YM6,

164 indicating the degradation of storage nutrients (Figure 2A). Meanwhile, downregulated proteins

165 were mainly involved in regulation of carbon, nitrogen and macromolecular metabolic processes

166 (alpha-amylase/trypsin inhibitor and transcriptional factors) when the Gr was 6\%. For the cellular component subclass, upregulated proteins involved in proteasome, endoplasmic reticulum membrane, and extracellular region were enriched in YM6. At the beginning of storage, enriched downregulated proteins were mainly associated with membrane component (YM45), but with an extended artificial ageing time (YM28), enriched downregulated proteins were mainly linked to nucleosome, chromatin and chromosome, and downregulated proteins in YM6 were mainly enriched in respiratory chain, ribosome and ribonucleoprotein complex categories (Figure 2B).

Molecular function analysis indicated that upregulated proteins participated in amylase activity,

hydrolase activity, cellulase activity and transporter activity, while down-regulated proteins were involved in peptidase regulatory activity, nutrient reservoir activity, structural constituents of 176 ribosome, enzyme regulator activity and protein dimerization/heterodimerization (Figure 2C). 
177 Protein domain analysis demonstrated that many upregulated proteins contained domains involved

178 in pathogenesis-related proteins, alpha-amylase and glycosyl hydrolase when Gr was 28\%,

179 whereas when Gr was 6\%, upregulated proteins were mainly associated with cytochrome c,

180 glycoside hydrolase, and 14-3-3 protein. Additionally, upregulated proteins with a mitochondrial

181 carrier domain were enriched in YM45, proteins with histone fold and histone H2 were abundant

182 in YM28, and proteins with 50S ribosomal protein, proteinase inhibitor, non-specific lipid-transfer

183 protein and bifunctional trypsin/alpha-amylase inhibitor/seed storage domains were enriched in

184 YM6 (Figure 3A). KEGG analysis indicated that upregulated proteins involved in MAPK

185 signaling pathway, signal transduction and plant pathogen interactions were mainly enriched when

186 Gr was $28 \%$ and $6 \%$, and upregulated proteins associated with glycan, amino acids, glutathione

187 metabolism, pentose phosphate pathway and starch and sucrose metabolism were enriched when

188 Gr was 6\%. Downregulated proteins related to protein processing in the endoplasmic reticulum

189 were enriched when Gr was $45 \%$, and proteins linked to oxidative phosphorylation and DNA

190 modification were downregulated following extended storage time (Figure 3B).

191 3.4. Classification of DEPs during artificial ageing

192 To better understand the functions of proteins, representative DEPs were classified into six groups

193 involving enzyme activity and regulation, nutrient reservoir activity, electron transport and signal

194 transduction, energy and metabolism, defense/stress responses and chromatin and ribosome (Table $1951)$.

196 Enzymes involved in starch hydrolytic activity and proteolysis such as alpha/beta-amylase, beta-

197 glucosidase, and proteasome subunit were upregulated, while alpha-amylase/trypsin inhibitor and 
proteinase inhibitor subtilisin-chymotrypsin were downregulated, which was inconsistent with the increased enzyme activities. Accompanying the increased levels of hydrolytic enzymes was the reduced abundance of storage proteins avenin, gliadin, gamma-hordein and oleosin. Additionally, proteins involved in electron transport and signal transduction including cytochrome c oxidase, and calcium-dependent protein kinase and 14-3-3 protein were upregulated. These results also indicated that proteins in energy and metabolism were differently regulated. Two downregulated ATP synthase submits were observed and glyceraldehyde-3-phosphate dehydrogenase that is involved in glycolysis was downregulated, whereas glucose-6-phosphate isomerase, 6phosphofructokinase, acyl-coenzyme A oxidase, and pyruvate kinase were upregulated. Malate dehydrogenase and succinate dehydrogenase that are involved in the tricarboxylic acid cycle were downregulated, whereas citrate synthase, and isocitrate dehydrogenase were upregulated. Additionally, glucose-6-phosphate 1-dehydrogenase that is involved in the pentose phosphate pathway was upregulated. Among the proteins involved in defense/stress responses, peroxidases and superoxide dismutases, protein disulfide-isomerases, non-specific lipid-transfer proteins, puroindoline-B, and L-ascorbate peroxidase were downregulated, whereas glutathione Stransferase, glutathione synthetase, pathogenesis-related protein, defensin-like protein, wheatwin2, and heat stress-associated DnaJ were upregulated. During accelerated ageing, proteins participating in chromatin and ribosome organization such as protein $\mathrm{H} 2 \mathrm{~A}$, histone $\mathrm{H} 2 \mathrm{~B}$, and the $40 \mathrm{~S}$ and $60 \mathrm{~S}$ ribosomal proteins were downregulated.

\section{Discussion}


218 It has been demonstrated that seed deterioration is accompanied by accumulation of reactive

219 oxygen species (ROS), lipid peroxidation, inefficient energy supply and degradation of stored

220 proteins and nucleic acids (Lee et al., 2012; McDonald, 1999; Rajjou et al., 2008; Yao et al., 2012).

221 Our present work showed that with extended storage time, increased number of DEPs were mainly

222 involved in nutrient reservoir activity, enzyme activity and regulation, defense/stress response, and

223 other processes in aged seeds (65 in YM45, 74 in YM28, and 871 in YM6) compared with

224 untreated seeds (YM97), which resulted in gradually decreased germination rates. Previous reports

225 also indicated that physiological properties in wheat can vary with the degree of hardness during

226 accelerated ageing. Additionally, the post-harvest storage-tolerance of soft and hard wheat was

227 different under the same storage conditions (Keskin et al., 2018; Zhang et al., 2017). Our current

228 results showed that the Gr of soft wheat seeds of the 'Yangmai 15' cultivar was higher than that

229 of hard wheat seeds of the 'Aikang 58' cultivar under the same storage conditions (Lv et al., 2016),

230 confirming the superior post-harvest storage-tolerance of soft wheat. Accompanying analysis of

231 the physiological changes, we performed a TMT-based dynamic quantitative analysis of proteomic

232 changes in the 'Yangmai 15' soft wheat cultivar during artificial ageing.

233 Wheat grain proteins accumulate during seed development and break down during seed ageing.

234 Our results indicated that the reduced abundance of storage proteins associated with processing

235 qualities (Rasheed et al., 2014) was consistent with that in hard wheat during artificial ageing (Lv

236 et al., 2016). The decreased abundance of storage proteins might lead to an inefficient energy

237 supply for seed germination. Additionally, oleosins that were previously found to be

238 downregulated in hard wheat and are known to function in germination (Huang, 1992) were also 
239 downregulated in the present work, consistent with the reduced Gr. A previous study showed that

240 alpha-amylase/trypsin inhibitors are expressed during germination and following wounding, and

241 they are beneficial to organ development (Dong et al., 2015). In our current results, the reduced

242 abundance of seven alpha-amylase/trypsin inhibitors and a subtilisin-chymotrypsin serine protease

inhibitor together with the increased activities of amylases and proteases during artificial ageing

might indicate that protection of wheat seeds is gradually diminished during seed deterioration.

Additionally, the upregulated acyl-coenzyme A oxidase, responsible for $\beta$-oxidation (Goepfert and

Poirier, 2007), was also upregulated during ageing, further indicating seed deterioration.

247 During accelerated ageing, proteins involved in electron transport, signal transduction, and energy and metabolism were differentially regulated. In animal cells, overexpression of cytochrome c oxidase, which functions in the final step of the electron transport chain, could lead to cell apoptosis (Sanchez-Alcazar et al., 2000). In the present work, cytochrome c oxidase subunit was upregulated, as was observed previously in maize seeds during accelerated ageing (Xin et al., 2011). Protein phosphorylation plays a key role in many signaling pathways including the responses to stresses such as heat shock, desiccation, peroxide and high salt stress, and calcium-dependent protein kinases and 14-3-3 proteins could facilitate the phosphorylation of target proteins (Trewavas, 2000). Their upregulation in the present study suggested that signal transduction may be disturbed, as occurs in maize seeds following accelerated ageing (Xin et al., 2011). In the present work, glyceraldehyde-3-phosphate dehydrogenase, malate dehydrogenase and succinate dehydrogenase that are involved in glycolysis (EMP) and the tricarboxylic acid 
260 changes known to occur in aged maize and hard wheat (Lv et al., 2016; Xin et al., 2011).

261 Compared to the downregulated enzymes associated glycolytic pathway-tricarboxylic acid cycle

262 in hard wheat (Lv et al., 2016), several enzymes involved in glycolysis, the pentose phosphate

263 pathway, and the tricarboxylic acid cycle were upregulated, including citrate synthase, isocitrate

264 dehydrogenase, glucose-6-phosphate isomerase, 6-phosphofructokinase, and pyruvate kinase

265 (Table 1). The EMP-TCA provides energy and carbon skeletons for other metabolic processes

during seed imbibition, and a recent report demonstrated that storage-tolerant seeds might have

higher EMP-TCA activity than storage-sensitive seeds (Chen et al., 2018). These results indicated that soft wheat seeds might have higher EMP-TCA activity than hard wheat seeds, indicating superior post-harvest storage-tolerance for soft wheat seeds.

To protect grains against various stresses such as oxidative stress, high temperature, and pathogen infection, several stress- and defense-related proteins are regulated during artificial ageing. Previous studies indicated that oxidative damage occurs during seed storage (Galleschi et al., 2002; Calucci et al., 2004). Seeds possess defense systems such as such as ascorbate and glutathione cycle to scavenge ROS and prevent oxidative damage. Thus, the storability of seeds is believed to be associated with the capacity to detoxify ROS. A decreased Gr is associated with an increase in ROS and a decrease in the activities of antioxidant enzymes such as peroxidases, catalases, ascorbate peroxidase, glutathione reductase, superoxide dismutase and glutathionerelated enzymes (Goel et al., 2003; Xin et al., 2014). In our current work, superoxide dismutase, 
281 However, our present study also indicated that glutathione S-transferase (GST) and glutathione 282 synthetase were upregulated compared with levels in hard wheat (Lv et al., 2016), and these 283 proteins were assigned to ROS detoxification and stress response function. The results indicated

284

285

286

287

288

289

290

291

292

293

294

295

296

297

298

299

300

301

that soft wheat seeds might possess a stronger antioxidant defense system than hard wheat seeds, consistent with a recent report showing that storage-tolerant seeds utilize GSTs for ROS detoxification and oxidative stress tolerance (Chen et al., 2018). These results might also help to explain why soft wheat displays superior post-harvest storage-tolerance storage compared with hard cultivars under the same storage conditions. Additionally, upregulation of proteins such as pathogenesis-related proteins and wheatwin2 in soft wheat served to protect against fungal invasion $(\mathrm{Ng}, 2004)$ during accelerated ageing might also contribute to the superior post-harvest storage-tolerance of soft wheat. DNA and histone proteins are important components of chromosome, and previous reports revealed accumulation of chromosome damage under different storage conditions (Rao et al., 1987; McDonald,1999). In our present work, decreased histone H2A/B levels during ageing might be responsible for chromosomal damage (Rao et al., 1987), and decreased abundance of 40/60S ribosomal proteins and unfolded protein response-associated protein disulfide-isomerases indicated diminished protein biosynthesis capacity (Kimura et al., 2015).

To investigate the mechanism of seed ageing, accelerated ageing conditions in which seeds deteriorate under high temperature and relative humidity were extensively employed to simulate natural ageing. Some authors questioned the physiological relevance of artificial ageing for short durations, whereas others concluded that controlled deterioration treatment can mimic molecular 
302 and biochemical events that occur during natural seed ageing (Galleschi et al., 2002; McDonald,

303 1999; Rajjou et al., 2008). Although accelerated ageing is unable to fully mimic natural ageing,

304 our present work provides dynamic proteomic insight into soft wheat seeds during accelerated

305 ageing.

\section{Conclusions}

In this study, dynamic physiological and proteomic changes in soft wheat seeds that occur

during accelerated ageing were investigated. The upregulated defense/stress-related proteins

including glutathione S-transferase, glutathione synthetase, wheatwin-2 and pathogenesis-related

proteins identified herein might be responsible for the superior post-harvest storage-tolerance

compared with hard cultivars under the same storage conditions. Our results identified potential

target proteins underlying the physiological changes and improved post-harvest storage-tolerance

of soft wheat during seed deterioration.

\section{Acknowledgments}

315 This work was supported by grants from the natural science foundation of China (31371850,

31631772023 and 31501575), natural science foundation of Henan province (162300410047), science

317 and technology development of Henan province (162102210191). Doctoral Scientific Research

318 Start-up Foundation from Henan University of Technology (2015QNJH06 and 2015BS016).

\section{Supporting Information}

Figure S1. SDS-PAGE analysis of seed embryos proteins during different storage times (A);

Peptide length distribution (B); Mass error distribution of all identified peptides (C);

Reproducibility analysis of three repeated trials by Pearson correlation coefficient (D). 
323 Table S1. Identification and annotation of proteins during accelerated ageing.

324

325

326

327

328

329

330

331

332

333

334

335

336

337

338

339

340

341

342

343

\section{References}

Aoyama T, Souri M, Kamijo T, Ushikubo S, Hashimoto T. 1994. Peroxisomal acyl-coenzyme a oxidase is a rate-limiting enzyme in a very long-chain fatty acid $\beta$-oxidation system. Biochemical and biophysical research communications 201: 1541-1547 DOI 10.1006/bbrc.1994.1879.

Calucci L, Capocchi A, Galleschi L, Ghiringhelli S, Pinzino C, Saviozzi F, Zandomeneghi M. 2004. Antioxidants, free radicals, storage proteins, puroindolines, and proteolytic activities in bread wheat (Triticum aestivum) seeds during accelerated aging. Journal of agricultural and food chemistry 52: 4274-4281 DOI 10.1021/jf0353741.

Capparelli R, Amoroso MG, Palumbo D, Iannaccone M, Faleri C, Cresti M. 2005. Two plant puroindolines colocalize in wheat seed and in vitro synergistically fight against pathogens. Plant Molecular Biology 58: 857-867 DOI 10.1007/s11103-005-8270-9.

Chen X, Yin G, Börner A, Xin X, He J, Nagel M, Liu X, Lu X. 2018. Comparative physiology and proteomics of two wheat genotypes differing in seed storage tolerance. Plant Physiology and Biochemistry 130: 455-463 DOI 10.1016/j.plaphy.2018.07.022.

Dong K, Zhen S, Cheng Z, Cao H, Ge P, Yan Y. 2015. Proteomic analysis reveals key proteins and phosphoproteins upon seed germination of wheat (Triticum aestivum L.). Frontiers in plant science 6: 1017 DOI 10.3389/fpls.2015.01017.

Galleschi L, Capocchi A, Ghiringhelli S, Saviozzi F, Calucci L, Pinzino C, Zandomeneghi M. 2002. Antioxidants, free radicals, storage proteins, and proteolytic activities in wheat (Triticum 
344 durum) seeds during accelerated aging. Journal of agricultural and food chemistry 50: 54505457 DOI 10.1021/jf0201430.

346 García-Olmedo F, Molina A, Segura A, Moreno M. 1995. The defensive role of nonspecific lipidtransfer proteins in plants. Trends in microbiology 3: 72-74 DOI 10.1016/S0966842X(00)88879-4.

Ge P, Hao P, Cao M, Guo G, Lv D, Subburaj S. 2013. iTRAQ-based quantitative proteomic analysis reveals new metabolic pathways of wheat seedling growth under hydrogen peroxide stress. Proteomics 13: 3046-3058. doi: 10.1002/pmic.201300042.

Goel A, Goel AK, Sheoran IS. 2003. Changes in oxidative stress enzymes during artificial ageing in cotton (Gossypium hirsutum L.) seeds. Journal of Plant Physiology 160: 1093-1100.

Huang AH. 1992. Oil bodies and oleosins in seeds. Annual review of plant biology 43: 177-200 
365

366

367

368

369

370

371

372

373

374

375

376

377

378

379

380

381

382

383

384

385

Karp NA, Huber W, Sadowski PG, Charles PD, Hester SV, Lilley KS. 2010. Addressing accuracy and precision issues in iTRAQ quantitation. Molecular \& Cellular Proteomics 9: 1885-1897 DOI10.1074/mcp.M900628-MCP200.

Keskin Ş, Yalçın E, Özkaya H. 2018. Effects of storage and granary weevil infestation on gel electrophoresis and protein solubility properties of hard and soft wheat flours. Journal of economic entomology 111: 1454-1460 DOI 10.1093/jee/toy041.

Kimura S, Higashino Y, Kitao Y, Masuda T, Urade R. 2015. Expression and characterization of protein disulfide isomerase family proteins in bread wheat. BMC plant biology 15: 73 DOI 10.1186/s12870-015-0460-2.

Lee J, Welti R, Roth M, Schapaugh WT, Li J, Trick HN. 2012. Enhanced seed viability and lipid compositional changes during natural ageing by suppressing phospholipase $\mathrm{D} \alpha$ in soybean seed. Plant biotechnology journal 10: 164-173 DOI 10.1111/j.1467-7652.2011.00650.x.

Lesage VS, Merlino M, Chambon C, Bouchet B, Marion D, Branlard G. 2011. Proteomes of hard and soft near-isogenic wheat lines reveal that kernel hardness is related to the amplification of a stress response during endosperm development. Journal of experimental botany 63: 10011011 DOI 10.1093/jxb/err330.

Lim TK. 2013. Triticum aestivum. In edible medicinal and non-medicinal plants. Springer, Dordrecht, 25: 385-415.

Lv Y, Zhang S, Wang J, Hu Y. 2016. Quantitative proteomic analysis of wheat seeds during artificial ageing and priming using the isobaric tandem mass tag labeling. PLoS One, 11(9), e0162851 DOI 10.1371/journal.pone.0162851. 
386

387

388

389

390

391

392

393

394

395

396

397

398

399

400

401

402

403

404

405

406

Mak Y, Willows RD, Roberts TH, Wrigley CW, Sharp PJ, Copeland L. 2009. Germination of wheat: a functional proteomics analysis of the embryo. Cereal chemistry 86: 281-289 DOI 10.1094/CCHEM-86-3-0281.

McDonald MB. 1999. Seed deterioration: physiology, repair and assessment. Seed Science Technology 27: 177-237.

Ng TB. 2004. Antifungal proteins and peptides of leguminous and non-leguminous origins. Peptides 25: 1215-1222 DOI 10.1016/j.peptides.2004.03.012.

Pasha I, Anjum FM, Morris CF. 2010. Grain hardness: a major determinant of wheat quality. Food Science and Technology International 16: 511-522 DOI 10.1177/1082013210379691.

Rajjou L, Lovigny Y, Groot SP, Belghazi M, Job C, Job D. 2008. Proteome-wide characterization of seed aging in Arabidopsis: a comparison between artificial and natural aging protocols. Plant Physiology 148: 620-641 DOI 10.1104/pp.108.123141.

Rao NK, Roberts EH, Ellis RH. 1987. Loss of viability in lettuce seeds and the accumulation of chromosome damage under different storage conditions. Annals of Botany 60: 85-96 DOI 10.1093/oxfordjournals.aob.a087425.

Rasheed A, Xia X, Yan Y, Appels R, Mahmood T, He Z. 2014. Wheat seed storage proteins: Advances in molecular genetics, diversity and breeding applications. Journal of Cereal Science 60: 11-24 DOI 10.1016/j.jcs.2014.01.020.

Rehman ZU, Shah WH. 1999. Biochemical changes in wheat during storage at three temperatures. Plant Foods for Human Nutrition 54: 109-117 DOI 10.1023/A:1008178101991.

Sanchez-Alcazar JA, Ault JG, Khodjakov A, Schneider E. 2000 Increased mitochondrial 
cytochrome c levels and mitochondrial hyperpolarization precede camptothecin-induced apoptosis in Jurkat cells. Cell death and differentiation 7: 1090-1100 DOI doi.org/10.1038/sj.cdd.4400740.

Trewavas A. 2000. Signal perception and transduction. Biochemistry and Molecular Biology of Plants. Buchanan B. B., Gruissem W., and Jones R. L., eds. Am. Soc. Plant Physiologists: Rockville, MD, pp. 930-987.

van Ulsen P, Kuhn K, Prinz T, Legner H, Schmid P, Baumann C. 2009. Identification of proteins

Xin X, Lin XH, Zhou YC, Chen XL, Liu X, Lu XX. 2011. Proteome analysis of maize seeds: the effect of artificial ageing. Physiologia plantarum 143: 126-138 DOI 10.1111/j.13993054.2011.01497.x

Xin X, Tian Q, Yin G, Chen X, Zhang J, Ng S, Lu X. 2014. Reduced mitochondrial and ascorbateglutathione activity after artificial ageing in soybean seed. Journal of plant physiology 171: 140-147 DOI 10.1016/j.jplph.2013.09.016. 
428 Yao Z, Liu L, Gao F, Rampitsch C, Reinecke DM, Ozga JA, Ayele BT. 2012. Developmental and 429 seed aging mediated regulation of antioxidative genes and differential expression of proteins 430 during pre-and post-germinative phases in pea. Journal of plant physiology 169: 1477-1488 $431 \quad$ DOI 10.1016/j.jplph.2012.06.001.

432 Zdobnov EM, Apweiler R. 2001. InterProScan-an integration platform for the signature433 recognition methods in InterPro. Bioinformatics 17: 847-848 DOI $434 \quad$ 10.1093/bioinformatics/17.9.847.

435 Zhang SB, Lv YY, Wang YL, Jia F, Wang JS, Hu YS. 2017. Physiochemical changes in wheat of 436 different hardnesses during storage. Journal of Stored Products Research 72: 161-165 DOI 437 10.1016/j.jspr.2017.05.002. 


\section{Figure captions}

440 Figure 1. $\mathrm{CO}_{2}$ concentration and germination rates of wheat seeds during artificial ageing.

441 Figure 2. Functional-enrichment-based clustering of DEPs (GO analysis). (A) biological process,

442 (B) cellular component and (C) molecular function. Each category of DEPs includes both up- and

443 down-regulated proteins. YM45/97 represents proteins displaying significant changes in Gr45\%

444 compared with Gr97\%; YM28/97 represents proteins displaying significant changes in Gr28\%

445 compared with Gr97\%; YM6/97 means proteins displaying significant changes in Gr6\% compared

446 with Gr97\%.

447 Figure 3. Functional-enrichment-based clustering of DEPs. (A) Protein domain and (B) KEGG

448 pathway. Each category includes both up- and down-regulated DEPs. YM45/97 represents proteins

449 displaying significant changes in Gr45\% compared with Gr97\%; YM28/97 represents proteins

450 displaying significant changes in Gr28\% compared with Gr97\%; YM6/97 represents proteins

451 displaying significant changes in Gr6\% compared with Gr97\%.

452 Table 1. The selected proteins with differential accumulation during seed ageing compared with 453 unaged seeds. 
Figure 1

$\mathrm{CO}_{2}$ concentration and germination rates of wheat seeds during artificial ageing.

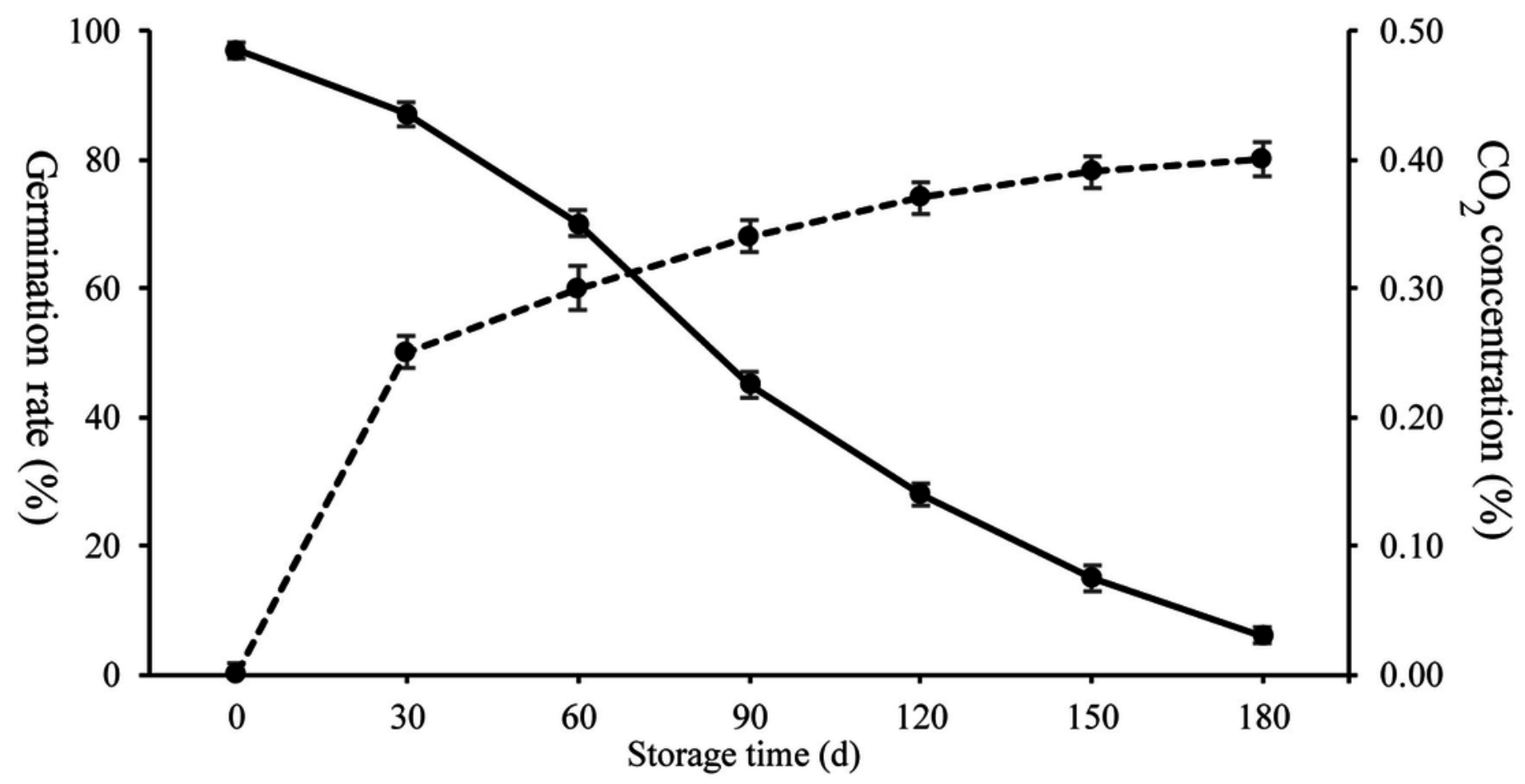

$\longrightarrow$ Germination rate (\%) $\quad-\cdots--\mathrm{CO}_{2}$ concentration (\%) 


\section{Figure 2}

Functional-enrichment-based clustering of DEPs (GO analysis). (A) biological process, (B) cellular component and (C) molecular function.

Each category of DEPs includes both up- and down-regulated proteins. YM45/97 represents proteins displaying significant changes in Gr45\% compared with Gr97\%; YM28/97 represents proteins displaying significant changes in Gr28\% compared with Gr97\%; YM6/97 means proteins displaying significant changes in Gr6\% compared with Gr97\%.
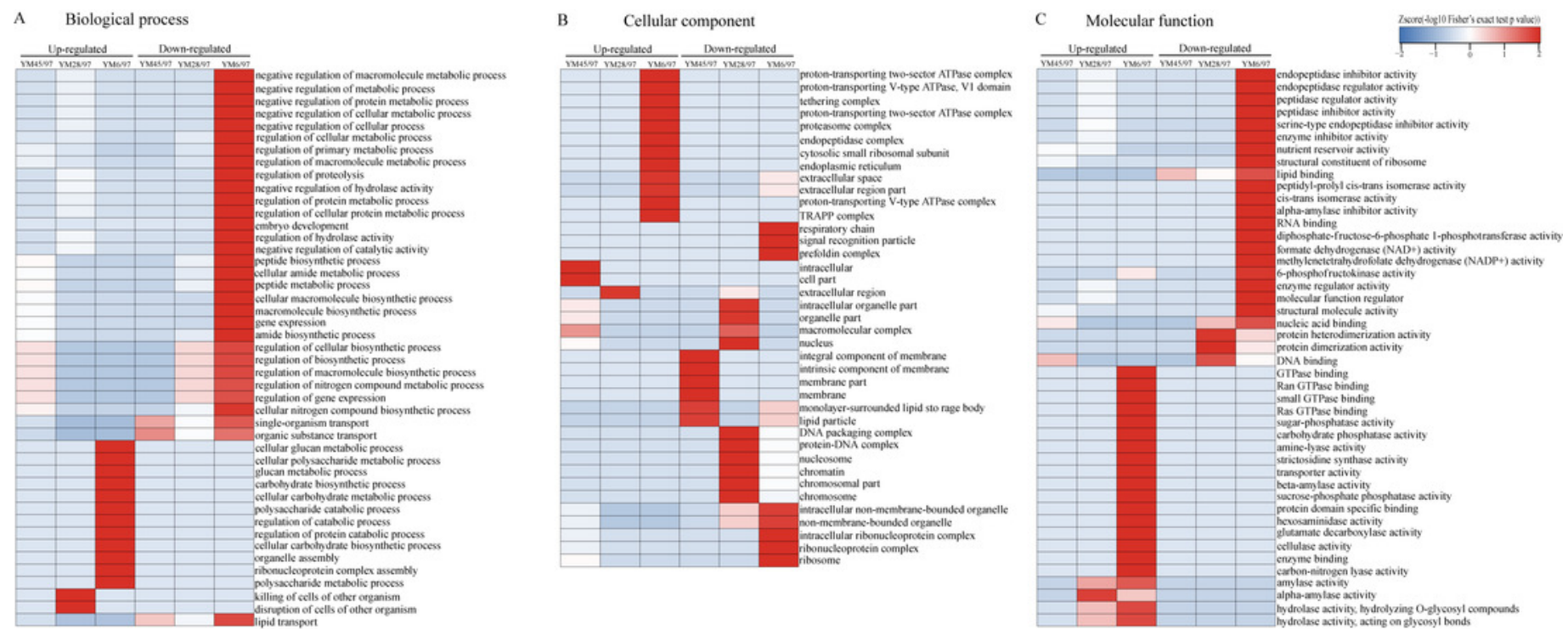


\section{Figure 3}

Functional-enrichment-based clustering of DEPs. (A) Protein domain and (B) KEGG pathway.

Each category includes both up- and down-regulated DEPs. YM45/97 represents proteins displaying significant changes in Gr45\% compared with Gr97\%; YM28/97 represents proteins displaying significant changes in Gr28\% compared with Gr97\%; YM6/97 represents proteins displaying significant changes in Gr6\% compared with Gr97\%.
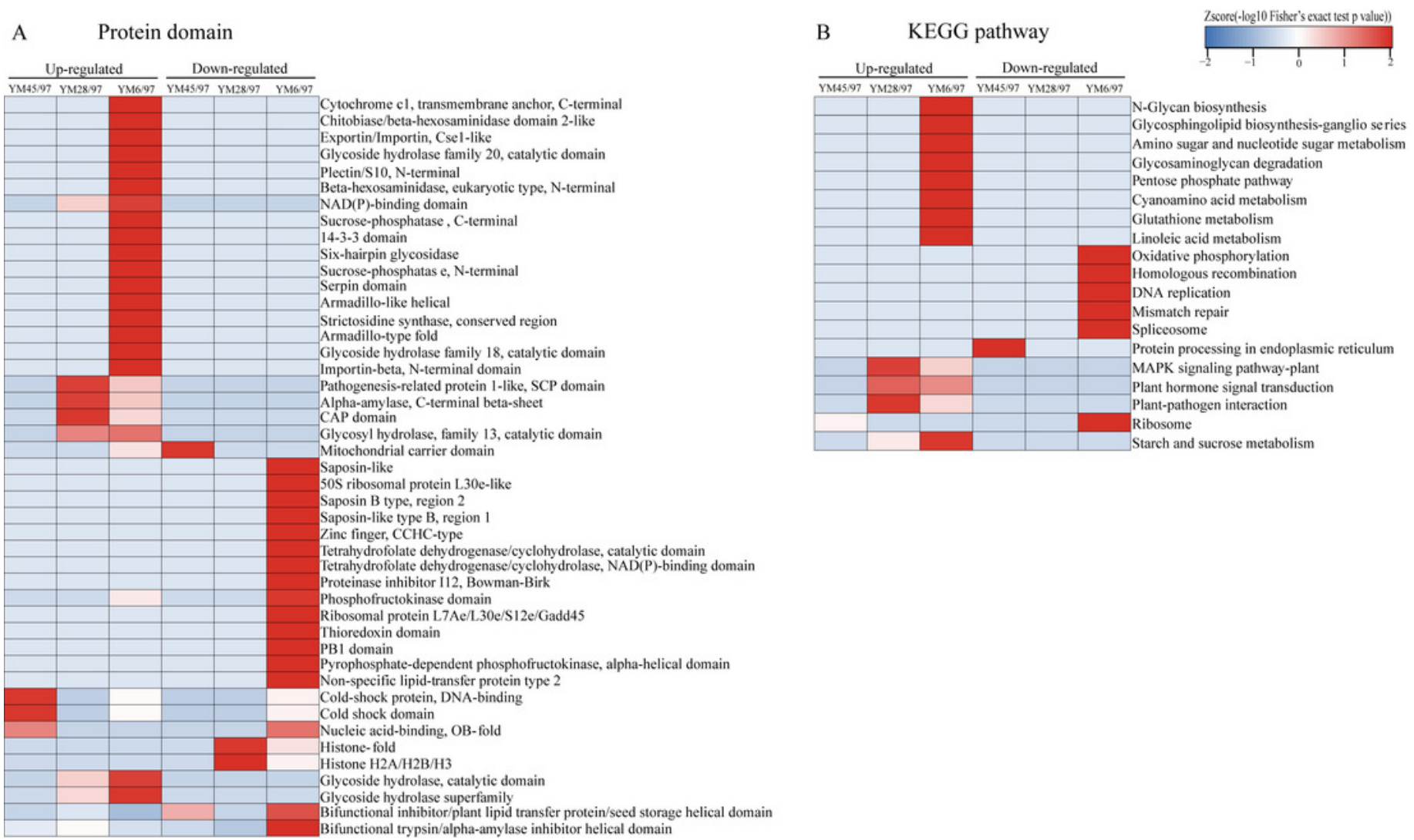


\section{Table $\mathbf{1}$ (on next page)}

The selected proteins with differential accumulation during seed ageing compared with unaged seeds. 
1 Table 1 The selected proteins with differential accumulation during seed ageing compared with unaged seeds.

\begin{tabular}{|c|c|c|c|c|c|}
\hline Protein accession & Protein description & Regulated type & Ratio & Stage & $\begin{array}{l}\text { MW } \\
{[\mathrm{kDa}]}\end{array}$ \\
\hline \multicolumn{6}{|l|}{$\begin{array}{l}\text { Enzyme activity } \\
\text { and regulation }\end{array}$} \\
\hline A0A1D5YNU4 & alpha-amylase isozyme $3 \mathrm{~A}$ & Up & $1.43,1.70$ & YM28,YM6 & 52.36 \\
\hline W5FHN7 & alpha-amylase isozyme $3 \mathrm{~A}$ & $\mathrm{Up}$ & $2.04,2.73$ & YM28,YM6 & 47.57 \\
\hline A0A1D5YFA7 & Beta-amylase & $\mathrm{Up}$ & 1.51 & YM6 & 55.32 \\
\hline A0A1D5XXC9 & Beta-amylase & $\mathrm{Up}$ & 1.54 & YM6 & 58.93 \\
\hline A0A1D5XGF4 & Beta-amylase & $\mathrm{Up}$ & 1.54 & YM6 & 56.77 \\
\hline W5B347 & beta-glucosidase & $\mathrm{Up}$ & $1.22,1.75$ & YM28,YM6 & 57.25 \\
\hline W5G0E6 & $\begin{array}{l}\text { proteasome subunit alpha } \\
\text { type-3 }\end{array}$ & Up & 1.27 & YM6 & 27.17 \\
\hline W5ENN5 & $\begin{array}{l}\text { proteasome subunit beta } \\
\text { type-4-like }\end{array}$ & $\mathrm{Up}$ & 1.27 & YM6 & 27.02 \\
\hline A0A1D5XZ64 & $\begin{array}{l}\text { proteasome subunit alpha } \\
\text { type-5-like }\end{array}$ & Up & 1.22 & YM6 & 25.88 \\
\hline P01083 & $\begin{array}{c}\text { alpha-amylase inhibitor } \\
0.28\end{array}$ & Down & 0.72 & YM6 & 16.80 \\
\hline Q43723 & $\begin{array}{l}\text { trypsin/alpha-amylase } \\
\text { inhibitor CMX1/CMX3 }\end{array}$ & Down & 0.81 & YM6 & 13.83 \\
\hline P16159 & $\begin{array}{l}\text { Alpha-amylase/trypsin } \\
\text { inhibitor CM16 }\end{array}$ & Down & 0.54 & YM6 & 15.78 \\
\hline A0A1D5UB33 & $\begin{array}{l}\text { alpha-amylase/trypsin } \\
\text { inhibitor CM1 }\end{array}$ & Down & 0.72 & YM6 & 21.49 \\
\hline A0A1D5Y0V2 & $\begin{array}{l}\text { alpha-amylase/trypsin } \\
\text { inhibitor CM3 }\end{array}$ & Down & 0.57 & YM6 & 17.31 \\
\hline P16851 & $\begin{array}{c}\text { Alpha-amylase/trypsin } \\
\text { inhibitor CM2 }\end{array}$ & down & 0.73 & YM6 & 15.46 \\
\hline P17314 & $\begin{array}{l}\text { Alpha-amylase/trypsin } \\
\text { inhibitor CM3 }\end{array}$ & down & 0.65 & YM6 & 18.22 \\
\hline A0A1D5SLP0 & $\begin{array}{c}\text { subtilisin-chymotrypsin } \\
\text { inhibitor } \\
\end{array}$ & Down & 0.49 & YM6 & 9.36 \\
\hline \multicolumn{6}{|l|}{$\begin{array}{l}\text { Nutrient reservoir } \\
\text { activity }\end{array}$} \\
\hline D6QZM5 & avenin-like b6 & Down & 0.83 & YM45 & 32.35 \\
\hline A0A1D6CWE4 & avenin-like b6 & Down & 0.71 & YM6 & 20.58 \\
\hline D2KFH1 & avenin-like a1 & Down & 0.63 & YM6 & 18.92 \\
\hline A0A1D6CWE1 & avenin-like a1 & Down & 0.60 & YM6 & 21.89 \\
\hline P0CZ08 & avenin-like a1 & Down & 0.59 & YM6 & 19.25 \\
\hline
\end{tabular}




\begin{tabular}{cccccc} 
M9TGF7 & gamma-gliadin & Down & 0.58 & YM6 & 37.16 \\
M9TK56 & gamma-gliadin & Down & 0.61 & YM6 & 41.20 \\
J7HT09 & alpha-gliadin A-III-like & Down & 0.51 & YM6 & 32.87 \\
\hline
\end{tabular}

2 Table 1 (continued)

\begin{tabular}{|c|c|c|c|c|c|}
\hline Protein accession & Protein description & $\begin{array}{l}\text { Regulated } \\
\text { type }\end{array}$ & Ratio & Stage & $\begin{array}{l}\text { MW } \\
{[\mathrm{kDa}]}\end{array}$ \\
\hline P04728 & $\begin{array}{c}\text { Alpha/beta-gliadin MM1- } \\
\text { like }\end{array}$ & Down & 0.49 & YM6 & 21.52 \\
\hline A0A1D5S109 & gamma-hordein-3-like & Down & 0.29 & YM6 & 23.67 \\
\hline A0A1D5T3T7 & gamma-hordein-3-like & Down & 0.39 & YM6 & 36.42 \\
\hline W5BE38 & Oleosin & Down & $0.68,0.59$ & YM45,YM6 & 16.31 \\
\hline A0A1D5UJY0 & Oleosin & Down & $0.68,058$ & YM45,YM6 & 18.22 \\
\hline A0A1D5ZZ07 & Oleosin & Down & 0.83 & YM6 & 16.90 \\
\hline A0A1D6CX50 & Acyl-coenzyme A oxidase & Up & 1.24 & YM6 & 73.97 \\
\hline \multicolumn{6}{|l|}{$\begin{array}{l}\text { Electron transport } \\
\text { and signal } \\
\text { transduction }\end{array}$} \\
\hline A0A1D5WWR8 & $\begin{array}{c}\text { putative cytochrome c } \\
\text { oxidase subunit }\end{array}$ & Up & 1.25 & YM6 & 8.99 \\
\hline Q6KCK6 & $\begin{array}{c}\text { calcium-dependent protein } \\
\text { kinase } 1\end{array}$ & Up & 1.20 & YM6 & 58.41 \\
\hline G5DFC5 & 14-3-3 protein & Up & 1.24 & YM6 & 29.97 \\
\hline L0GED8 & 14-3-3 protein & Up & 1.32 & YM6 & 29.27 \\
\hline \multicolumn{6}{|l|}{$\begin{array}{l}\text { Energy } \\
\text { metabolism }\end{array}$} \\
\hline W5BEP1 & ATP synthase subunit $d$ & Down & 0.78 & YM6 & 19.55 \\
\hline W5GLU0 & ATP synthase subunit o & Down & 0.82 & YM6 & 25.57 \\
\hline A0A1D6BD14 & $\begin{array}{c}\text { Glyceraldehyde-3- } \\
\text { phosphate dehydrogenase }\end{array}$ & Down & 0.78 & YM6 & 43.73 \\
\hline A0A1D5ST38 & Malate dehydrogenase & Down & 0.81 & YM6 & 35.48 \\
\hline A3KLL4 & Malate dehydrogenase & Down & 0.83 & YM6 & 35.49 \\
\hline A0A1D6BI29 & Succinate dehydrogenase & Down & 0.76 & YM6 & 30.98 \\
\hline W5H1Q1 & Citrate synthase & Up & 1.21 & YM28 & 52.56 \\
\hline A0A1D6RKR9 & Isocitrate dehydrogenase & $\mathrm{Up}$ & 1.28 & YM6 & 46.32 \\
\hline A0A1D5UPI1 & $\begin{array}{c}\text { Glucose-6-phosphate 1- } \\
\text { dehydrogenase }\end{array}$ & Up & 1.50 & YM6 & 57.82 \\
\hline W5FY62 & $\begin{array}{l}\text { Glucose-6-phosphate } \\
\text { isomerase }\end{array}$ & Up & 1.22 & YM6 & 67.06 \\
\hline A0A1D5UP90 & 6-phosphofructokinase & $\mathrm{Up}$ & 1.25 & YM6 & 50.73 \\
\hline W5G100 & Pyruvate kinase & Up & 1.49 & YM6 & 57.42 \\
\hline
\end{tabular}




\begin{tabular}{cccccc}
\hline $\begin{array}{c}\text { Defense/stress } \\
\text { response }\end{array}$ & & & & & \\
A0A1D5S2L6 & peroxidase & Down & 0.71 & YM28 & 37.48 \\
A0A1D5WX80 & peroxidase & Down & 0.80 & YM6 & 35.76 \\
A0A1D5TMJ6 & peroxidase & Down & $0.78,0.81$ & YM28,YM6 & 29.77 \\
A0A1D5TAW7 & Superoxide dismutase & Down & 0.78 & YM6 & 21.19 \\
\hline
\end{tabular}

3 Table 1 (continued)

\begin{tabular}{|c|c|c|c|c|c|}
\hline $\begin{array}{c}\text { Protein } \\
\text { accession }\end{array}$ & Protein description & $\begin{array}{c}\text { Regulated } \\
\text { type }\end{array}$ & Ratio & Stage & $\begin{array}{c}\text { MW } \\
{[\mathrm{kDa}]}\end{array}$ \\
\hline A0A1D5XFA3 & L-ascorbate peroxidase & Down & 0.72 & YM6 & 26.09 \\
\hline Q10464 & Puroindoline-B & Down & 0.75 & YM6 & 16.79 \\
\hline W5D2I6 & $\begin{array}{l}\text { Non-specific lipid- } \\
\text { transfer protein }\end{array}$ & Down & $0.80,0.78,0.44$ & YM45,YM28,YM6 & 11.23 \\
\hline A0A1D5WSS8 & $\begin{array}{l}\text { Non-specific lipid- } \\
\text { transfer protein }\end{array}$ & Down & $0.77,0.43$ & YM45, YM6 & 14.81 \\
\hline Q1KMV0 & $\begin{array}{l}\text { Non-specific lipid- } \\
\text { transfer protein }\end{array}$ & Down & $0.79,0.77,0.46$ & YM45,YM28,YM6 & 11.12 \\
\hline W5D2I6 & $\begin{array}{l}\text { Non-specific lipid- } \\
\text { transfer protein }\end{array}$ & Down & $0.80,0.78,0.44$ & YM45,M28,YM6 & 11.23 \\
\hline A0A1D5T8E9 & $\begin{array}{l}\text { Non-specific lipid- } \\
\text { transfer protein }\end{array}$ & Down & 0.44 & YM6 & 21.11 \\
\hline A0A1D5ZPD0 & $\begin{array}{l}\text { Non-specific lipid- } \\
\text { transfer protein }\end{array}$ & Down & 0.45 & YM6 & 12.13 \\
\hline P24296 & $\begin{array}{l}\text { Non-specific lipid- } \\
\text { transfer protein }\end{array}$ & Down & 0.45 & YM6 & 11.90 \\
\hline A0A1D5XQK2 & $\begin{array}{l}\text { Non-specific lipid- } \\
\text { transfer protein }\end{array}$ & Down & 0.46 & YM6 & 11.97 \\
\hline Q2PCD2 & $\begin{array}{l}\text { Non-specific lipid- } \\
\text { transfer protein }\end{array}$ & Down & 0.46 & YM6 & 12.25 \\
\hline P82901 & $\begin{array}{l}\text { Non-specific lipid- } \\
\text { transfer protein }\end{array}$ & Down & 0.47 & YM6 & 7.05 \\
\hline A0A1D5UG33 & $\begin{array}{l}\text { Non-specific lipid- } \\
\text { transfer protein }\end{array}$ & Down & 0.51 & YM6 & 18.44 \\
\hline A0A1D5Y7A7 & $\begin{array}{l}\text { Non-specific lipid- } \\
\text { transfer protein }\end{array}$ & Down & 0.53 & YM6 & 11.86 \\
\hline A0A1D5SG95 & $\begin{array}{l}\text { Non-specific lipid- } \\
\text { transfer protein }\end{array}$ & Down & 0.62 & YM6 & 12.61 \\
\hline C3UZE5 & $\begin{array}{l}\text { Pathogenesis-related } \\
\text { protein 1-like }\end{array}$ & Up & 1.36 & YM28 & 17.64 \\
\hline A0A1D5YCS8 & pathogenesis-related & Up & $1.85,1.76$ & YM28,YM6 & 26.67 \\
\hline
\end{tabular}


protein 1-like

\begin{tabular}{cccccc} 
P20159 & defensin-like protein 2 & Up & 1.35 & YM28 & 5.15 \\
O64393 & Wheatwin-2 & Up & 1.23 & YM28 & 15.87 \\
P30110 & $\begin{array}{c}\text { Glutathione S- } \\
\text { transferase 1 } \\
\text { Glutathione S- }\end{array}$ & $\mathrm{Up}$ & $1.33,1.70$ & YM28,YM6 & 25.83 \\
Q8RW01 & $\begin{array}{c}\mathrm{Up} \\
\text { transferase }\end{array}$ & $\mathrm{Up}$ & 1.20 & YM6 & 25.20 \\
\hline
\end{tabular}

4 Table 1 (continued)

\begin{tabular}{|c|c|c|c|c|c|}
\hline $\begin{array}{c}\text { Protein } \\
\text { accession }\end{array}$ & Protein description & $\begin{array}{l}\text { Regulated } \\
\text { type }\end{array}$ & Ratio & Stage & $\begin{array}{c}\text { MW } \\
\text { [kDa] }\end{array}$ \\
\hline W5G485 & Glutathione synthetase & $\mathrm{Up}$ & 1.27 & YM6 & 52.9 \\
\hline \multicolumn{6}{|l|}{ Other proteins } \\
\hline Q43312 & protein $\mathrm{H} 2 \mathrm{~A}$ & Down & $0.76,0.56$ & YM28,YM6 & 13.93 \\
\hline W5E8H6 & histone $\mathrm{H} 2 \mathrm{~B}$ & Down & 0.83 & YM28 & 16.31 \\
\hline W5F9T2 & histone $\mathrm{H} 2 \mathrm{~B}$ & Down & 0.83 & YM28 & 16.49 \\
\hline W5EBF3 & histone $\mathrm{H} 2 \mathrm{~B}$ & Down & 0.59 & YM6 & 33.13 \\
\hline W5C8N6 & 40S ribosomal protein S6 & Down & 0.56 & YM6 & 28.46 \\
\hline A0A1D5UFM0 & $\begin{array}{l}\text { 40S ribosomal protein } \\
\text { S12 }\end{array}$ & Down & 0.72 & YM6 & 15.23 \\
\hline Q7X748 & $60 \mathrm{~S}$ ribosomal protein $\mathrm{L} 3$ & Down & 0.77 & YM6 & 44.62 \\
\hline W5FSM8 & $\begin{array}{l}\text { 60S ribosomal protein } \\
\text { L17-1 }\end{array}$ & Down & 0.75 & YM6 & 19.49 \\
\hline A0A1D5X7C5 & $\begin{array}{l}\text { Protein disulfide- } \\
\text { isomerase }\end{array}$ & Down & 0.74 & YM6 & 53.25 \\
\hline A0A1D5Y681 & $\begin{array}{l}\text { Protein disulfide- } \\
\text { isomerase }\end{array}$ & Down & 0.76 & YM6 & 56.02 \\
\hline A0A1D5XQP7 & $\begin{array}{l}\text { Protein disulfide- } \\
\text { isomerase }\end{array}$ & Down & 0.83 & YM6 & 54.19 \\
\hline
\end{tabular}

5 